that was done. He commenced blue pill, digitalis, ipecacuanha, and opium; and he ultimately took wine freely. The sputa became more purulent, and ultimately much tinged with blood. Since the relapse nothing had at all controlled the attack; he lived, however, till the 26th of February, when his powers were quite exhausted. Unfortunately, a postmortem examination was not made; but there could be no doubt, from the abundant puriform streaks, of the existence of purulent infiltration or possible abscess in the right lung; and there were marks of considerable pleuritic effusion on the left side of the chest; the sides had been repeatedly blistered.

CASE 23. Severe Croup.-A child, aged three years, a stout, fine boy, had a sudden and most severe attack of croup. He was bled to slight faintness. The subsequent treatment consisted in emetic doses of antimony, calomel, leeches, and altimately senega and ammonia. Drowsiness, with ultimate restlessness, came on, unrelieved by nourishment and stimulus; the symptoms of oppression or prostration of the nervous centres increased, and the child died on the thirteenth day after the seizure, the obstruction in the trachea remaining to the very last.

The cases recorded above are not selected, but are all the cases under my care in which general bloodletting was employed during the last eighteen months. In November, 1851, I began, in order to determine more accurately the results of cases in which bleeding was used, to make a note of every case that was bled. Nor were the cases selected to produce a favourable result, but were all those that appeared clearly to warrant or demand the employment of this remedy. In Cases $4,5,6,7,8,10,19$, and 20, life was in all probability saved by this measure, and in most of the others decided relief and amendment was secured; the last two were the only fatal ones. In Case 22-pleuro-pneumonia-if I had known at the first the extent of this man's driuking habits, I might have been inclined to prefer local depletion; but I was wrongly informed at that time. The rapid resolution, however, of the pneumonia which followed the bleeding, the long time he lived after the second attack, and the failure of all other remedies to relieve him, make it doubtful whether the venesection might not have been repeated on the relapse. Case 23-croup-came under my notice after the child was bled; but as it appeared to me to have been the correct treatment, I have included it in the list. If a practitioner is constantly and daily using venesection, he must be doing great harm; but if he never employs it, he must every now and then lose a case which certainly might have been saved. Suppose, for example, one hundred cases of acute inflammation: eighty, perhaps, of these may be so mild in character, or so limited in extent, as not to threaten life, and to undergo spontaneous cure; ten might be resthenic, and the chance of recovery be destroyed by venesection; another ten I will suppose sthenic, and bleeding (general) the remedy that will save life. Now, if a man is so enthralled by routine that he must either bleed every case, or not bleed at all, he had certainly better not bleed in any case; otherwise, while he saves the ten sthenic cases, he will destroy the ten asthenic, and injure the remaining eighty. The practitioner shonld seek to discipline his mind to observation and discrimination; and while he relies on the records of authority and the light of experience, to be guided in his treatment by the character of each individual case; and, in the instance of bleeding, not to reject it in cases where it is really needed, because it is unnecessary in some and injurious in others, but to employ it in cases proper for its use-viz., sthenic cases, of recent origin, occurring in unimpaired constitutions. I can easily understand the prejudice that seems to exist in some hospitals to general bleeding. If we look to the medical cases, acute inflammations are admitted after some considerable time has elapsed in the progress of the complaint; it must be very rarely that a man applies at a hospital at the origin of the acute inflammation; he goes there when his complaint has existed some time; the mischief is done, and the inflammation is on the wane. To apply the remedy then is to weaken the powers of endurance and reparation, and to take away the only chance of life; but I expect that it is only a tithe of these cases that, worn down in strength, and with extensive local damage, are thus seen, and supposed to show that bleeding was unnecessary. The weekly returns of mortality, with their large proportion of deaths from acute inflammation, will answer the question, "Where are the nine?"

The successful treatment of severe external inflammation by stimulus, which is so constantly seen, does not favour a corresponding mode of procedure in internal inflammations, either in principle or in fact. The plan of action in giving stimulants largely in severe erysipelas or compound fractures is to support the powers, and prevent them sinking, during the progress of the inflammation, the mischief it produces, and the subsequent reparative action. This answers very well in a leg or an arm, because it is not necessary to life; and however great the damage, if the powers can be maintained, the patient may do well; but this is not the case if the heart or a lung is inflamed; their action being indispensable to life, the only hope of the patient doing well is either that the inflammation is itself limited, or capable of being checked and controlled in its progress, to prevent the damage, which, if it occurs to a certain extent, will certainly destroy life by its interference with the action of a vital organ.

Brunswick-terrace, Commercial-road East, 1853.

\section{REPORT OF THREE CASES OF ASIATIC CHOLERA.}

By HENRY BEHREND, Esq., M.R.C.S., SURGEON TO THE LIYERPOOY DISPENSARIES, \&C.

I BEG to direct the particular attention of the profession to the following case, as, independently of its being, as I believe, the first genuine example of Asiatic cholera that has appeared in this country, there are some interesting points in the history that are well worthy notice.

On the 22nd of August, 1853, I was summoned to an Emigrant Boarding House to see a German emigrant. I found him suffering from a tolerably severe attack of choleraic diarrhoea, rice-coloured evacuations, vomiting, and painful cramps in the legs and abdomen. The diarrhoea had been going on unchecked for some days. I ordered him calomel and opium, and in two days he was much better. The day subsequent to his seizure, his two children were similarly attacked, but in a milder degree, and they were at once cured by a few doses of chalk mixture with laudanum. Three days afterwards, (the $26 \mathrm{th}$,) his wife was suddenly and violently seized with vomiting and purging, followed in a few hours by cramps and smart febrile symptoms. As I was desirous of fully testing the power of the varions remedies, I ordered her the dilute sulphuric acid, which gave her prompt and effectual relief.

At eight P.M. on the 30th of August, I was hurriedly sent. for to the same boarding-house, to see another German emigrant of the name of Wilhelm S- He had been $a$ fellow-passenger with my other patients in the steamer from Hamburgh about a fortnight before this date. The day after leaving Hamburgh slight diarrhoa came on, but he thought it of so trifling a nature as not to be worthy of mention; it continued, however, uninterruptedly, neither increasing nor diminishing, up to this date. He is twenty-five years of age, sober, steady, and of active and industrious habits, and was on his way to America to take a commercial situation. On the 30 th of Angust he was in his usual health and spirits, and at three in the afternoon dined heartily upon soup, meat, and vegetables. About an hour afterwards, he complained of pain in the stomach, and was seized with violent romiting and purging. The attack was so sudden and severe as to strike him down at once. The symptoms rapidly increased in intensity, and were accompanied by cramps in the inferior extremities and abdomen. The evacuations were of the true choleraic character, having the appearance of thin rice-water, with albuminous flakes floating about in it.

I was not sent for until eight P.M., four hours after the seizure, and at once recognised the true features and the utter hopelessness of the case. He was in bed, and in an exhausted condition; was perfectly rational and sensible, but spoke in a husky tone of voice. His chief sources of complaint were of thirst, cramp in the abdomen, and an uninterrupted diarrhcea; vomiting had almost entirely ceased; there was no pulse; the entire surface of the body was covered with a cold sweat; the hands were ice-cold, the nails bluish, and the features fixed and rigid. He had passed no urine since the commencement of the attack. I ordered the free administration of brandy-and-water, warmth to the surface, and calomel and opium, though the case was evidently beyond the reach of medicine.-Ten P.M.: Saw him again with Dr. Vose. Within the last two hours he has undergone a marked change for the worse: his voice has sunk to a whisper; the featuree are pinched and appear elongated; the skin of the face and 
hands has shrunk, and is perfectly cold; he is very restless, and tosses about in bed incessantly. The diarrhoea has almost ceased; no more vomiting. He continues quite rational, and complains of oppression about the chest, and difficulty of breathing. He retained his faculties until three the next morning, but became more restless, and complained of increased oppression. At four o'clock he was delirious for about an hour, after which coma came on, accompanied by stertorous breathing. The entire surface of the body became livid and cold, and he gradually sank, until twelve at noon, when death put an end to the painful scene. During the night there were no evacuations whatsoever, and not a drop of urine was passed during the course of the attack.

The most remarkable feature in this case is its origin. There can be but little doubt that $S$ - brought the seeds of the malady with him from Hamburgh, where it is at present extremely rife; and it is more than probable that the ther cases would have pursued an equally fatal course had they not been checked in time. I confess that I look upon these Emigrant Lodging-houses with a great degree of suspicion, and believe that they will be mainly instrumental in bringing the cholera to our shores, as, in spite of all the sanitary regulations which are enforced upon them, they offer abundant facilities for the reception and spread of disease. Measures should certainly be at once adopted to check any symptoms of diarrhce that may present themselves in immigrants from ports where the cholera is known to prevail; but this can only be effected by regulations of the local Boards of Health, and must be rendered compulsory upon the proprietors of the houses.

Another point of interest is the extreme facility with which, in the first instances, the symptoms of choleraic diarrhœe yielded to the simple astringent remedies. It is, I believe, generally admitted that the great majority of cases are perfectly amenable to treatment, provided they are seen before collapse has come on.

The fatal case was as strongly and characteristically marked as any which came under the notice either of Dr. Vose or myself during the course of the last epidemic.

The two following cases of Asiatic cholera-one of which has already proved fatal-having since occurred in the same emigrants' lodging-house in which the case above reported took place, it is advisable to put them on record, with a view to outaining a correct history of the epidemic.

Ferdinand S—, aged thirty-six, a native of West Prussia left Hamburgh on the 31st of Angust, and arrived here via Hull on the 3rd of September in perfect health, having had no premonitory symptoms on the voyage. He supped heartily, and went to bed on the night of the $3 \mathrm{rd}$ in good health, but was disturbed at one o'clock A.M. by violent purging, which continued throughout the morning, and at eight A.M. vomiting came on. The evacuations consisted of a thin fluid, at first rather darkish-coloured, but speedily assuming the usual ricewater appearance, and free from albuminous flakes. At ten A.M. cramps in the legs supervened. I first saw him at this time, and found him complaining of great lassitude and weakness; he had just vomited, but neither the vomiting nor the purging was continuous; pulse at the wrist barely perceptible; surface of the skin warm and moist; voice natural but weak; extremities warm; no pain about the abdomen or chest; occasional cramps in the feet. He had taken two doses of the chalk mixture with laudanum. I ordered ten grains of calomel with five of Dover's powder to be taken every hour, and mustard-poultices to the lower extremities and abdomen. -One P.M.: Decided change for the worse; quite pulseless; surface cold; skin shrunken; voice sunk to a whisper; diarrhoea and vomiting occasional; intense thirst; answers questions very reluctantly. To continiue the powders every hour, and to take of the following mixture two tablespoonfuls every hour: oil of turpentine, two drachms; the yolk of an egg; tincture of opium, two drachms; distilled water, eight ounces: mix. Stimulant applications to the surface, and brandy to be administered internally.-Seven P.M.: No improvement; state of collapse well-marked; he is roused with difficulty; voice completely lost; features pinched; eyes sunk deep in the orbits; skin quite cold; diarrhœe occasional; vomiting ceased. To continue the medicines every hour.

5th.-Nine A.M.: Remains in a state of collapse; features, if anything, more shrunken; has regained his voice, but speaks in a thick, husky tone; vomiting, diarrhœa, and cramps have ceased; extreme weakness, and inclination to sleep. To continue the treatment, but to take the powders and mixture every second hour.-Three P.M.: Surface of the body warmer pulse perceptible at the wrist, but exceedingly weak; answer, questions more readily, and in a better voice, but he is very lethargic; no return of the symptoms, and no complaint of pain. Has taken a little soup for the first time since the seizure.

6th.-Nine A.M.: Has slept all night and is drowsy, doubtless from the opium; pulse better, but still very weak; skin cool; no diarrhoea or vomiting. To continue the medicines every fourth hour. In spite of the large quantity of calomel he has taken, there are no signs of salivation. I have hopes of this man's recovery, though he remains in a dangerous state.

Sophia S - the wife of the last patient, aged thirty-four, within a fortnight of her confinement, accompanied her husband from Hamburgh here, and slept with him on the night of September 3rd in which he was attacked. She was then in her usual state of health, and had not suffered from diarrhœa during the voyage.

At eleven A.M. on the 4 th of September-her husband having been attacked ten hours previously, and having remained by his side during that time-she was seized with sudden vomiting and purging, but not having seen the evacuations at this time, $I$ cannot speak as to their nature. She felt weak, and was extremely depressed in spirits, owing to her husband's dangerous state, and her approaching confinement. Ordered her the compound chalk mixture with tincture of opium in full doses, and ten grains of calomel immediately, and to be repeated every hour. The patient grew rapidly worse; her features assumed the unmistakable appearance of the true type of cholera; and when I next saw her at seven P.M., she was in the stage of collapse; tossing about in bed, and complaining of cramps in the abdomen; no perceptible pulse; surface cold; vomiting occasional; the bowels were incessantly discharging a stream of fluid, darker-coloured than in either of the preceding cases, and having albuminous flakes floating upon the surface. To continue the powders, and to take the turpentine and laudanum mixture prescribed for her husband. Local and internal stimulants.

5th.-Nine A.m.: The medicines were administered regularly during the night; she did not sleep; was very restless, and complained of oppression about the chest and dyspnoea; surface of the body cold; pulse imperceptible; features shrunken and rigid; the skin of the hands remarkably shrunk and blue; no evacuations or cramp during the night. She died at noon.

These two cases differ from the first in one important point - the absence of any premonitory symptoms, the disease not having shown itself until after their arrival here, whereas - had suffered from diarrhœa-slight it is true, yet persistent - for a fortnight previous. I am, nevertheless, of opinion, that they brought the malady with them from the Continent; and regarding all the cases as imported ones, do not apprehend the spread of the epidemic from the occurrence of these isolated examples. The chief feature of interest, in a scientific point of view, is their direct connexion with Prussia and Hamburgh, where the epidemic has been for some time known to exist.

Liverpool, August, 1853.

\section{CASES IN PRIVATE PRACTICE. Bx W. TIFFIN ILIFF, JUN., Esq., Kennington.}

\section{Sanguineods Effosion resembling Fungus Hematodes} OF THE THIGH.

Mr. J. M. Y _ , aged fifty, a gentleman of spare frame, rather bilious temperament, of temperate habits, and generally in the enjoyment of good health, came under my care on the 5th of March, 1851, complaining of pain of a rheumatic character in the muscles of the upper and outer part of the right thigh. On the second visit, he directed attention to a swelling near the seat of pain; this, on uncovering the limb, was at once apparent, equal to about the half of a small apple in size, and situated at the junction of the middle and lower thirds, almost in the centre, though rather towards the outer edge of the rectus; it was deep-seated, and to the touch much resembled enlarged bursa; it was not very movable, rather tender, and the temperature over it slightly increased; no external discoloration, no enlargement of the veins. It, was now ascertained that five or six months before, he had struck the thigh against the step of an omnibus in descending from the outside, and that pain and some degree of stiffness resulted, which had never entirely subsided. He took no notice 